\title{
Properties of a novel series of inhibitors of rumen methanogenesis; in vitro and in vivo experiments including growth trials on 2,4-bis (trichloromethyl)-benzo [1, 3]dioxin-6-carboxylic acid
}

\author{
By A. DAVIES, H. N. NWAONU, G. STANIER \\ AND F. T. BOYLE \\ Imperial Chemical Industries PLC, Pharmaceuticals Division, Alderley Park, \\ Macclesfield, Cheshire SK10 4TG
}

(Received 29 September 1980 - Accepted 8 January 1982)

\begin{abstract}
1. A procedure for measuring methane production by rumen contents incubated anaerobically in vitro is described. Assessments of methane production in vivo, in both sheep and cattle, were made by withdrawal of rumen contents and measuring their capacity to produce methane in vitro.

2. Many members of a series of 6-substituted 2,4-bis (trichloromethyl)-benzo[1,3]dioxins were potent inhibitors of methanogenesis by rumen contents in vitro. The most potent compound inhibited methane production by $70 \%$ or more at a concentration of $1 \mu \mathrm{g} / \mathrm{ml}$ (approximately $2.5 \mu \mathrm{mol} / \mathrm{l}$ ).

3. Two compounds, namely the 6-carboxylic acid (ICI 13409) and the 6-carboxamide (ICI 43586), caused a large inhibition of methanogenesis sustained for many hours, following a single intrarumen injection in sheep or cattle. Inhibition was maintained for long periods by single daily dosing directly into the rumen or by dietary administration.

4. In a 28-week growth trial in beef cattle inclusion of ICI 13409 in the concentrate element of the diet, at a level of $6 \mathrm{mg} / \mathrm{kg}$ body-weight, improved live-weight gain by $8.0 \%(P<0.05)$ with respect to untreated animals whilst reducing food intake by $5.0 \%(P<0.05)$. Smaller and not statistically-significant effects were seen with this compound at $3 \mathrm{mg} / \mathrm{kg}$ body-weight and with the antibiotic monensin (Romensin; Elanco PLC). All treatments significantly improved the retention of dietary energy into the carcass, offal and intestinal tracts of the trial animals and significantly reduced the quantity of methane eructed into expired gases.
\end{abstract}

Up to $10 \%$ of the energy of ruminant diets is converted to methane which is eructed. The idea that specific inhibition of rumen methanogenesis should lead to conservation of the hydrogen used in methane synthesis has been repeatedly argued (cf. Czerkawski \& Breckenridge, 1975 a). This $\mathrm{H}$ could be used for synthesis of reduced end products, e.g. propionic and butyric acids, with benefit to the host animal. In reported studies with inhibitors of methanogenesis, Rufener \& Wolin (1968) and Sawyer et al. (1974), amongst others, used respectively carbon tetrachloride and bromochloromethane in their experiments. These compounds have the disadvantage of volatility and even toxicity to the host animal. DDT is another potent inhibitor of methanogenesis (McBride \& Wolfe, 1971) which is toxicologically unattractive.

The property of inhibiting methanogenesis does not lie only in the field of halogenated hydrocarbons, however, since trichloroacetamide (Trei et al. 1971), chloral (Van Nevel et al. 1969), trichloroethanol and many of its esters (Czerkawski \& Breckenridge, 1975a) are all highly effective in vitro. Czerkawski \& Breckenridge $(1975 b)$ found that trichloroethyl adipate and trichloroethyl pivalate administered to sheep at $120-300 \mathrm{mg}$ daily inhibited methane production by up to $90 \%$, while Johnson (1972) found that $2 \mathrm{~g}$ hemiacetal of chloral and starch daily gave up to $80 \%$ inhibition of methanogenesis in sheep.

In some instances addition of inhibitors of methanogenesis to ruminant diets has given no improvements in performance or equivocal results. For instance, Clapperton (1977) found that trichloroethyl adipate depressed food intake and growth rate slightly; furthermore the effect on methanogenesis was lost after the first 2 weeks of dosing. The over-all conclusion was that the additive had no beneficial effect. A slight but not statisticallysignificant improvement in food conversion was reported by Trei et al. (1971) following 
inclusion of trichloroacetamide at $80 \mathrm{~g} /$ ton in the diet fed to lambs during a $90 \mathrm{~d}$ trial; the greatest effect was found during the first $30 \mathrm{~d}$ of the trial. In contrast Trei et al. (1972) found that the hemiacetal of chloral and starch, whilst also depressing food intake, slightly increased growth rate in lambs but doses of 1 and $2 \mathrm{~g}$ additive $/ \mathrm{kg}$ food were required to maintain statistically-significant improvements in food conversion efficiency over 3 months. In a cattle trial high inclusion levels $(2 \mathrm{~g} / \mathrm{kg})$ of this additive were also used. Food intake was depressed by $9 \%$ but food conversion efficiency was improved by $6 \%$ (Cole \& McCroskey, 1975).

Thus, whilst many inhibitors of rumen methanogenesis have been found, some are difficult to use because of volatility, others are known to be toxic and the remaining ones tested in long-term animal experiments tend to lose their effectiveness unless used in high doses. An underlying trend with all is a depression in food intake.

The work described here was designed to test large numbers of chemical compounds for ability to inhibit methanogenesis in vitro, to check the activity of the best inhibitors in animals, first in the short term then in the long term and finally to conduct growth trials to determine whether or not compounds capable of sustained inhibition of in vivo methanogenesis would have any benefit on animal performance.

\section{EXPERIMENTAL}

\section{Assay of compounds in vitro}

Samples of rumen contents were taken at approximately 09.30 hours from steers provided with rumen fistulas and given $1 \mathrm{~kg}$ concentrate each morning ( 08.30 hours) together with hay provided ad lib. from 08.30 until 16.30 hours. Equal quantities of fluid from two animals were pooled, filtered through three layers of gauze and used within $60 \mathrm{~min}$.

Strained rumen fluid $(9 \mathrm{ml})$ was dispensed into wide-mouthed McCartney bottles together with sucrose solution $(10 \mathrm{~g} / 1$ water $)(1 \mathrm{ml})$. Test compounds were dissolved or suspended in dimethylsulphoxide at $10 \mathrm{mg} / \mathrm{ml}$. Portions of these solutions were added to give final concentrations $30,10,3$ or $1 \mu \mathrm{g} / \mathrm{ml}$. Control bottles were included with respectively, no additions, $30 \mu \mathrm{l}$ dimethylsuphoxide, $1 \mu \mathrm{l}$ carbon tetrachloride. Each bottle was sealed with a Subaseal and the air was displaced by inserting two 21 gauge needles, one connected to a cylinder of nitrogen, passing gas through for $30 \mathrm{~s}$, and venting to atmosphere via the other needle. Nitrogen was chosen as gas phase since it gave the possibility of measuring carbon dioxide production. A mixed $\mathrm{CO}_{2}-\mathrm{N}_{2}$ gas, however, is a better imitation of the in vivo situation.

The broths were incubated for $3 \mathrm{~h}$ at $39^{\circ}$ then cooled in ice-water. The composition of the gas phase was then determined by gas-liquid chromatography (Stanier \& Davies, 1981) but using a chart recorder instead of the chromatographic data processor.

Results are expressed as percentage inhibition of methane production, with respect to that in the control bottles. The results were discarded and the test repeated if the controls produced less than $5 \mathrm{ml}$ methane/l or the inhibition by carbon tetrachloride was less than $90 \%$.

\section{Assay of compounds in vivo}

Response to single doses of compound. Samples of rumen contents were withdrawn from rumen-fistulated Suffolk cross sheep of approximately $30 \mathrm{~kg}$ live weight immediately before and at $1,2,3,4,6$ and $24 \mathrm{~h}$ after intraruminally dosing the test compound. The compound was dissolved in dimethylsulphoxide at $10 \mathrm{mg} / \mathrm{ml}$ and the appropriate volume of solution was added to $10 \mathrm{~g}$ Tween $80 / 1$ water $(10 \mathrm{ml})$. The mixture was vigorously shaken and immediately injected through the fistula, the sample bottle and injection syringe were rinsed with $10 \mathrm{ml}$ water which was also injected intraruminally. Dosing was always calculated on a ratio, compound weight $(\mathrm{mg})$ : live weight $(\mathrm{kg})$. 
The diet was $2.75 \mathrm{~kg}$ chopped hay which was offered to the animal immediately after dosing and residue, if any, was removed $6 \mathrm{~h}$ later. Methane production was determined by incubating portions $(10 \mathrm{ml})$ of the samples of rumen contents for $3 \mathrm{~h}$ at $39^{\circ}$ under an atmosphere of $\mathrm{N}_{2}$ as described in the in vitro assay system with the omission of the sucrose solution.

The percentage inhibition of methane production, with respect to the 'before-dosing' production, corrected for the variation in methane production with time in an untreated animal was calculated. The maximum percentage inhibition and the time during which there was greater than $50 \%$ inhibition are quoted.

\section{Response to multiple doses of compound}

(1) Intraruminal administration. The procedure described previously was followed; but the animals were dosed on several successive days. The same feeding regimen was used. The frequency of sampling was reduced after 2-6 d to twice daily (before and $1 \mathrm{~h}$ after dosing). The volatile fatty acid concentration of the samples of rumen contents was determined by gas-liquid chromatography (Stanier \& Davies, 1981) but using a Pye DP80 Integrator instead of the chromatography data processor.

(2) Dietary administration. Solutions $(1 \mathrm{mg} / \mathrm{ml})$ of the compound in ethanol were poured over cattle concentrate ('Denkovit' coarse mix; Rank, Hovis and McDougal) at least $12 \mathrm{~h}$ before feeding; the diet was exposed to the atmosphere to allow the ethanol to evaporate. The concentrate ( $100 \mathrm{~g}$ for sheep, $1 \mathrm{~kg}$ for cattle) was offered to the animals and, when eaten, the rest of the diet (hay 400; flaked maize 400 ; soya-bean meal 100; molasses 75 ; minerals and vitamins $25 \mathrm{~g} / \mathrm{kg}$ thoroughly mixed and cubed) as given ad lib. but any food remaining $6 \mathrm{~h}$ later was removed and the animals were fasted overnight. A group of similar animals fed non-medicated concentrate served as the control and was sampled simultaneously with the medicated group. Samples of rumen contents were taken as described previously. With the sheep, six treated animals were compared with a group of six untreated animals; the first treatment was $60 \mathrm{mg} / \mathrm{d}$ of compound and after $14 \mathrm{~d}$ the dose was reduced to $30 \mathrm{mg} / \mathrm{d}$ for a further $14 \mathrm{~d}$. The results from the untreated animals have been divided into two corresponding $14 \mathrm{~d}$ periods. With cattle two groups of three animals received respectively 4 and $6 \mathrm{mg} / \mathrm{kg}$ body-weight per $\mathrm{d}$ and results from them were compared with two untreated animals.

\section{Conduct of growth trials}

Eighty Friesian calves weighing 90-140 kg were penned in groups of five in slatted floor pens. They were acclimatized to their accommodation and to a diet of $2.5 \mathrm{~kg}$ cattle concentrate ('Denkovit' coarse mix; Rank, Hovis and McDougal) fed individually at approximately 08.30 hours whilst restrained by yokes. After this had been consumed the animals were released and allowed to eat hay ad lib. on a group basis. They were weighed weekly before feeding and after 3 months they were subdivided into five groups matched for both live-weight and growth rate. One group was slaughtered to provide information on empty body-weight and percentage of water and fat in the carcass. The remaining groups were assigned to, respectively, non-medicated (negative control) diet with ICI 13409 at 3 and $6 \mathrm{mg} / \mathrm{kg}$ live-weight daily and monensin (Romensin, Elanco PLC) $0.5 \mathrm{mg} / \mathrm{kg}$ live-weight up to $200 \mathrm{~kg}$ thereafter $100 \mathrm{mg}$ /animal per $\mathrm{d}$. Each group was sub-divided into four pens of four animals on the basis of approximately equal aggregate weight.

The consumption of concentrate was recorded daily, some animals refused to eat all the concentrate during the first 2 weeks of treatment; the hay consumed by each pen of four animals was recorded weekly. Each bale provided was weighed and the quantity not consumed, when the animals were moved to the weighing crate, was also weighed. The animals were weighed weekly before feeding on the concentrate. After each weighing the 
quantity of medicated diet (containing $1200 \mathrm{~g}$ ICI 13409/tonne or $200 \mathrm{~g}$ monensin/tonne) supplied to each animal to maintain a constant dose per $\mathrm{kg}$ live weight was adjusted, and a corresponding alteration was made to the quantity of non-medicated food supplied to maintain the total at $2.5 \mathrm{~kg} /$ animal per $\mathrm{d}$.

A check on the ability of the treatments to reduce methane production was made by placing the heads of four animals from each treatment group in turn into a box $1200 \times 640 \times 600 \mathrm{~mm}$ fitted with a canvas collar $400 \mathrm{~mm}$ diameter at the rear face of the box tapering to $250 \mathrm{~mm}$ over its length of $600 \mathrm{~mm}$. The open end of the collar was fitted with a draw cord which was used to pull the collar fairly-tightly round the neck of the animal. Air was withdrawn from the box at $70 \mathrm{l} / \mathrm{min}$ which ensured that all leaks were inward and after $10 \mathrm{~min}$ the concentration of methane in the exhaust was determined by gas-liquid chromatography (this technique was a modification of that of Bergman, 1964). The same four pens (one per group) of four animals were used for each determination, the animals were analysed randomly within each pen, the pens were analysed in inverse order on alternate occasions, although a rotational sequence would have been more precise.

\section{Statistical analysis of the cattle growth trial}

The sixteen pens were laid out as a $4 \times 4$ Latin Square. An Analysis of Variance (ANOVA) was performed on the pen mean responses allowing for the effects of the rows and columns of the Latin Square and the treatment groups. Treatment means were compared to the control using Student's $t$-tests with 1 -sided significance levels where the standard error was derived from the residual mean square in the ANOVA.

\section{RESULTS}

In vitro and in vivo tests on derivatives of 2,4-bis (trichloromethyl)-benzo $[1,3]$ dioxin Small quantities of many compounds containing trichloromethyl groups were found in the Alderley Park compound collection. These were tested at concentrations of $100 \mu \mathrm{g} / \mathrm{ml}$ and so many inhibited methane production by more than $50 \%$ that they had to be tested again at lower concentrations. Few compounds retained the ability to inhibit methane production at low concentration but amongst them were a number of 6-substituted derivatives of 2,4-bis(trichloromethyl)-benzo[1,3]dioxin. More derivatives of this series were synthesized. Test results are shown in Table 1.

A wide variety of substituents were compatible with ability to inhibit methane production at $1 \mu \mathrm{g} / \mathrm{ml}$. The highly-acidic sulphonic acid derivative was only weakly active at $30 \mu \mathrm{g} / \mathrm{ml}$. Basic substituents, e.g. amine, were compatible with good activity but addition of large lipophilic substituents reduced activity, as in the acylated secondary amine or the propionyl-substituted hydrazone. Esterification or amidation of the carboxylic acid derivative tended to reduce activity but these effects were only apparent at $1 \mu \mathrm{g} / \mathrm{ml}$.

The requirements for activity in vivo were much more critical. Sustained inhibitors of methane production at $1 \mathrm{mg} / \mathrm{kg}$ dose were only found with the carboxylic acid and carboxamide derivatives. Relatively small alterations in partition coefficient or proton donor capacity resulted in first a loss of persistence of effect and secondly in the extent of inhibition of methane production. With some substituents, notably the 6-chloro and 6-sulphonamide derivatives, increasing the dose gave a good persistent inhibition. Further tests were restricted to the carboxylic acid and carboxamide derivatives.

\section{Response of sheep to multiple doses of compound}

5-d dosing with 2,4-bis(trichloromethyl)-benzo[1,3]dioxin-6-carboxamide. Results are shown in Table 2. Methane production in the untreated animals showed a diurnal variation with a maximum 1-2 $\mathrm{h}$ after feeding and a minimum $10 \mathrm{~h}$ later. In contrast methane production 
Table 1. Biological activity of members of the series of 2,4-bis(trichloromethyl)-benzo [1,3]dioxins substituted at 6 position

\begin{tabular}{|c|c|c|c|c|c|c|c|c|}
\hline \multirow[b]{3}{*}{ ICI no. } & \multirow[b]{3}{*}{ Substituent group } & \multirow{2}{*}{\multicolumn{4}{|c|}{$\begin{array}{l}\text { Percentage inhibition } \\
\text { of in vitro production } \\
\text { of methane at various } \\
\text { concentrations }(\mu \mathrm{g} / \mathrm{ml})\end{array}$}} & \multicolumn{3}{|c|}{$\begin{array}{l}\text { Inhibition of methane production } \\
\text { in vivo as measured in vitro }\end{array}$} \\
\hline & & & & & & \multirow{2}{*}{$\begin{array}{l}\text { Maximum } \\
\text { percentage } \\
\text { observed }\end{array}$} & \multirow{2}{*}{$\begin{array}{c}\text { Duration } \\
\text { inhibition } \\
50 \%(\mathrm{~h})\end{array}$} & \multirow{2}{*}{$\begin{array}{c}\text { Dose } \\
(\mathrm{mg} / \mathrm{kg})\end{array}$} \\
\hline & & 30 & 10 & 3 & 1 & & & \\
\hline 13408 & $-\mathrm{NO}_{2}$ & 90 & 74 & 64 & NT & 0 & - & 3.0 \\
\hline 13409 & $-\mathrm{COO}^{-}$ & 82 & 85 & 85 & 68 & 80 & 6 & 1.2 \\
\hline 42315 & $-\mathrm{SO}_{3}^{-}$ & 40 & NT & NT & NT & NT & - & - \\
\hline 42317 & $-\mathrm{SO}_{2} \mathrm{NH}_{2}$ & 91 & 80 & 76 & 73 & 71 & 24 & $2 \cdot 0$ \\
\hline 43306 & $-\mathrm{COCH}_{3}$ & 92 & 88 & 52 & 28 & 0 & - & $2 \cdot 0$ \\
\hline 43478 & $-\mathrm{CHO}$ & 82 & 76 & 78 & 40 & NT & - & - \\
\hline 43538 & $\mathrm{CH}_{3} \dot{\mathrm{C}}=\mathrm{NNH}_{2}$ & 75 & NT & NT & NT & NT & - & - \\
\hline 43539 & $\mathrm{CH}_{3} \mathrm{C}=\mathrm{NNHCOC}_{3} \mathrm{H}_{7}$ & 19 & NT & NT & NT & NT & - & - \\
\hline 43569 & $-\mathrm{CH}=\mathrm{NNHCOC}_{3} \mathrm{H}$, & 70 & NT & NT & NT & NT & - & - \\
\hline 43586 & $-\mathrm{CONH}_{2}$ & 80 & 85 & 72 & 12 & 68 & 24 & 1.2 \\
\hline 104156 & $-\mathrm{COOCH}_{2} \mathrm{CCl}_{3}$ & 82 & 75 & 34 & NT & 53 & 6 & $2 \cdot 0$ \\
\hline 105105 & $-\mathrm{COCl}$ & 92 & 89 & 88 & 77 & 58 & 2 & 1.0 \\
\hline 105106 & $-\mathrm{COOC}_{2} \mathrm{H}_{5}$ & 90 & 81 & 83 & 40 & $\mathbf{0}$ & - & 1.0 \\
\hline 105378 & $-\mathbf{H}$ & 85 & 68 & 85 & 69 & 44 & - & 1.0 \\
\hline 105446 & $-\mathrm{NH}_{2}$ & 84 & 80 & 74 & 70 & 33 & - & 3.0 \\
\hline 105447 & $-\mathrm{CH}_{2} \mathrm{OH}$ & 88 & 83 & 81 & 75 & 75 & 1 & 1.0 \\
\hline 105648 & $-\mathrm{NHCOCH}_{3}$ & 89 & 76 & 0 & NT & 58 & 1 & $1 \cdot 0$ \\
\hline 106296 & $-\mathrm{CONHNH}_{2}$ & 75 & 70 & 80 & 10 & 27 & - & 3.0 \\
\hline 106297 & $-\operatorname{CON}\left(\mathrm{C}_{2} \mathrm{H}_{5}\right)_{2}$ & 79 & 73 & 70 & 57 & 54 & 1 & $1 \cdot 0$ \\
\hline 106298 & $-\mathrm{Cl}$ & 73 & 68 & 62 & 17 & $\left\{\begin{array}{r}71 \\
0\end{array}\right.$ & 24 & $\begin{array}{l}3.0 \\
1.0\end{array}$ \\
\hline
\end{tabular}

NT, not tested.

in the treated animals was minimal shortly after dosing and feeding, returning to a maximum immediately before the next treatment. The daily mean value was minimal on the third day, increased on the fourth and fifth days but had still not returned to its initial level on the eighth day, that is $3 \mathrm{~d}$ after the last treatment. These last two values are single observations only. The rumen concentrations of volatile fatty acids were markedly altered by treatment, that of acetic acid being depressed and propionic acid raised. The biggest effect was seen on day 2 . Both the changes in volatile fatty acids and methane are compatible with the compound having an initial effect on the microbial population of the rumen followed by a steady compensatory alteration to the population. This experiment did not indicate what the new steady-state situation might be so it was followed by a longer-term experiment.

5-week dosing with 2,4-bis(trichloromethyl)-benzo[1,3]dioxin-6-carboxylic acid (ICI 13409). The dose selected was $1 \mathrm{mg} / \mathrm{kg}$ body-weight and this was administered intraruminally in a single dose, given before feeding, daily for 4 weeks. Thereafter the dose was reduced to $0.5 \mathrm{mg} / \mathrm{kg}$ for a further week. The pattern of methane production found in the previous experiment was observed. Minimum methane production, 0.8 to $1.2 \mathrm{ml} / 1$ of methane produced in a $3 \mathrm{~h}$ in vitro incubation, was found shortly after dosing, and feeding in the treated animals, this rising to a maximum immediately before the next feed and dosing of compound, with maximal production shortly after feeding in the control animals. The average value for methane production in the treated animal was approximately $25 \%$ of that 
Table 2. Effect of intrarumen administration of 2,4-bis (trichloromethyl)-benzo [1,3]dioxin6-carboxamide to sheep over $5 \mathrm{~d}$. The dose was $1.2 \mathrm{mg} / \mathrm{kg}$ on day 1 followed by $0.9 \mathrm{mg} / \mathrm{kg}$ on days 2, 3, 4 and 5

\begin{tabular}{|c|c|c|c|c|c|c|c|c|}
\hline & Group... & \multicolumn{3}{|c|}{ Control } & \multicolumn{4}{|c|}{ Treated } \\
\hline \multicolumn{9}{|c|}{$\begin{array}{l}\text { (Mean production of methane ( } \mathrm{ml} / 1 \text { measured in vitro); values in parentheses indicate minimum and } \\
\text { maximum) }\end{array}$} \\
\hline & $\begin{array}{l}\text { Before 1st dose } \\
\text { Day: } 1 \\
2 \\
3 \\
4 \\
5 \\
6 \\
7 \\
8\end{array}$ & $\begin{array}{r}11 \\
10 \\
11 \\
10 \\
11 \\
10 \\
11 \\
9 \\
9\end{array}$ & $\begin{array}{l}(7.5- \\
(7 \cdot 5- \\
(9 \cdot 5- \\
(11.0 \\
(9 \cdot 0- \\
(7.2-\end{array}$ & $\begin{array}{l}\text {.0) } \\
.0) \\
.0) \\
2 \cdot 0) \\
.0) \\
.0)\end{array}$ & $\begin{array}{l}0 \\
5(1 \cdot 2- \\
7(0 \cdot 8- \\
2(0 \cdot 6- \\
9(0 \cdot 4- \\
5(1 \cdot 0- \\
9(3 \cdot 2- \\
0 \\
6\end{array}$ & & & \\
\hline \multicolumn{9}{|c|}{$\begin{array}{c}\text { (Mean rumen concentrations (mmol/l) of volatile fatty acids and molar percentages of acetic, propionic and } \\
\text { butyric acids) }\end{array}$} \\
\hline \multirow[t]{2}{*}{ Group... } & & \multicolumn{3}{|c|}{ Control } & \multicolumn{4}{|c|}{ Treated } \\
\hline & A & $\mathbf{P}$ & B & $\begin{array}{l}\text { Total } \\
\text { VFA }\end{array}$ & A & $\mathbf{P}$ & B & $\begin{array}{l}\text { Total } \\
\text { VFA }\end{array}$ \\
\hline Before 1st dose & $66 \cdot 8$ & $25 \cdot 3$ & 7.9 & $40 \cdot 0$ & $61 \cdot 2$ & $31 \cdot 9$ & 8.9 & 43.6 \\
\hline Day: 1 & $67 \cdot 0$ & $25 \cdot 6$ & $7 \cdot 4$ & $55 \cdot 5$ & $54 \cdot 0$ & $38 \cdot 0$ & $8 \cdot 0$ & $68 \cdot 2$ \\
\hline 2 & $66 \cdot 3$ & $25 \cdot 9$ & $7 \cdot 8$ & $61 \cdot 1$ & $50 \cdot 9$ & $41 \cdot 0$ & $8 \cdot 1$ & $70 \cdot 4$ \\
\hline 3 & $67 \cdot 5$ & 24.9 & $7 \cdot 6$ & 73.0 & 53.9 & $38 \cdot 4$ & 7.7 & 73.9 \\
\hline 4 & $69 \cdot 3$ & $23 \cdot 2$ & $7 \cdot 5$ & $78 \cdot 6$ & $59 \cdot 0$ & $33 \cdot 4$ & $7 \cdot 6$ & $63 \cdot 5$ \\
\hline 5 & $68 \cdot 3$ & 23.9 & $7 \cdot 8$ & $67 \cdot 7$ & $58 \cdot 1$ & $33 \cdot 3$ & 8.6 & $58 \cdot 0$ \\
\hline 6 & $67 \cdot 0$ & $25 \cdot 8$ & $7 \cdot 2$ & $58 \cdot 2$ & $61 \cdot 5$ & $30 \cdot 2$ & $8 \cdot 3$ & $60 \cdot 2$ \\
\hline 7 & $64 \cdot 9$ & $25 \cdot 9$ & $9 \cdot 2$ & $75 \cdot 8$ & $61 \cdot 6$ & $29 \cdot 1$ & $9 \cdot 3$ & $90 \cdot 6$ \\
\hline 8 & $70 \cdot 7$ & $21 \cdot 2$ & $8 \cdot 1$ & $86 \cdot 0$ & $62 \cdot 4$ & $28 \cdot 1$ & $9 \cdot 5$ & $84 \cdot 1$ \\
\hline
\end{tabular}

in the control in the first 3 weeks, and increased slightly in the fourth and fifth weeks whilst that in the control, having been fairly steady for 3 weeks, decreased in both the fourth and fifth weeks (Table $\dot{3}$ ).

With regard to the rumen volatile fatty acid concentration there was a tendency for the treated animals to have a higher content of propionic acid and a lower content of acetic acid than the control.

This experiment demonstrated that dosing with ICI 13409 was effective in reducing methane production over a 5-week period. It can be argued that the effect of the dosing at $0.5 \mathrm{mg} / \mathrm{kg}$ during the fifth week was not strictly relevant since it followed 4 weeks of dosing at $1 \mathrm{mg} / \mathrm{kg}$, but this did illustrate that a decrease, whether planned or not, in the dose would not lead immediately to loss of effect.

A second experiment using ICI 13409 dosed intraruminally at $0.5 \mathrm{mg} / \mathrm{kg}$ showed that the methane production determined in vitro averaged $4.6 \mathrm{ml} / 1$ during 1 week whilst that of the untreated animals averaged $11.6 \mathrm{ml} / \mathrm{l}$. During the next $4 \mathrm{~d}$ the dose of ICI 13409 was decreased to $0.25 \mathrm{mg} / \mathrm{kg}$, methane production in the treated animal increased slightly to $5.1 \mathrm{ml} / 1$ whilst that of the untreated animal decreased to $6.2 \mathrm{ml} / 1$. Thus an intraruminal dose of $0.5 \mathrm{mg} / \mathrm{kg}$ appears to be adequate. 
Table 3. Effect of intrarumen administration of 2,4-bis(trichloromethyl)-benzo[1,3]dioxin6-carboxylic acid to sheep over 5 weeks at a daily dose of $1 \mathrm{mg} / \mathrm{kg}$ body-weight

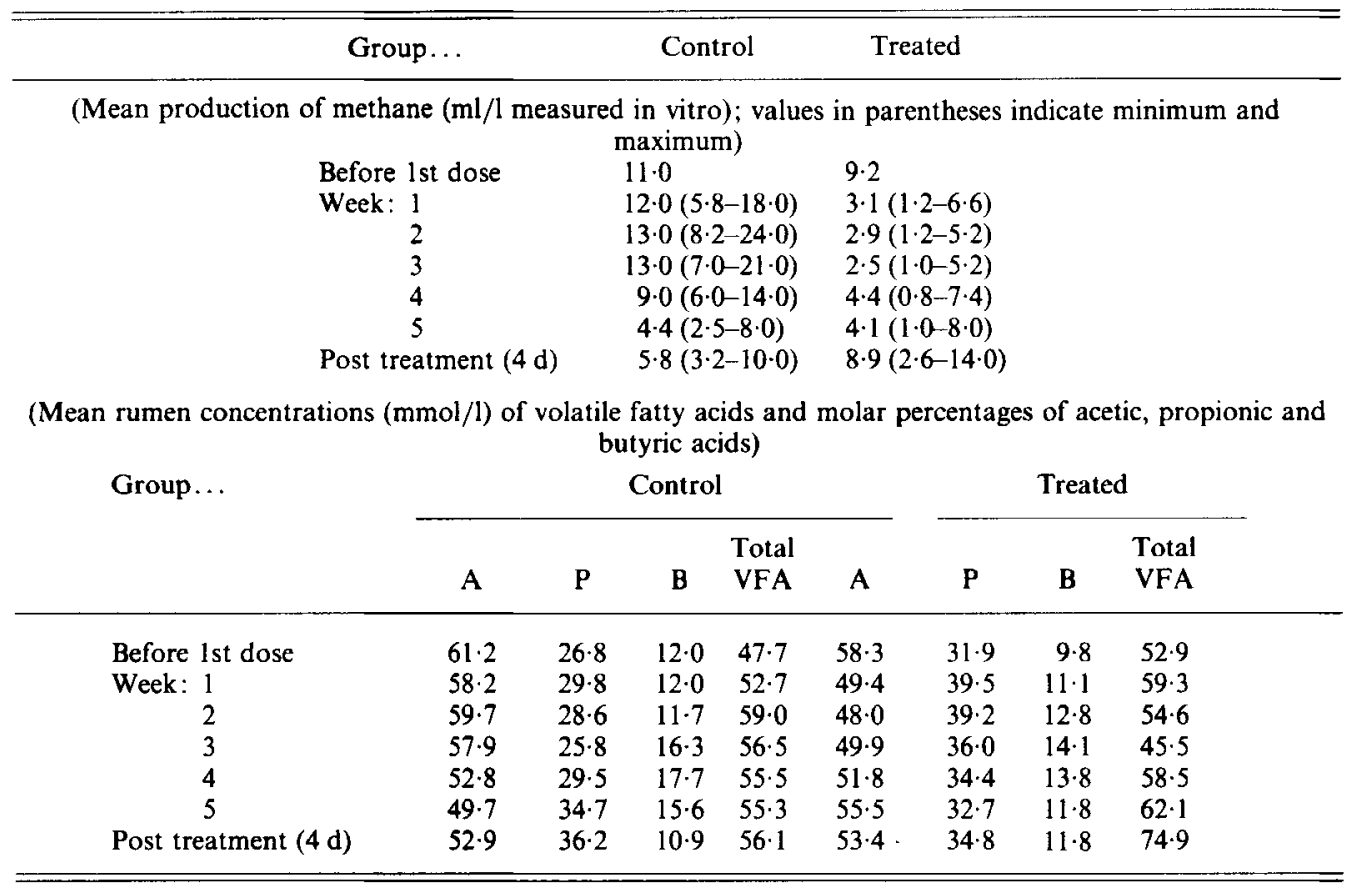

Response to ICI 13409 administered in the diet

Preliminary experiments indicated that the rate at which animals consumed the medicated diet influenced the quantity of ICI 13409 required to inhibit methane production. Two approaches were used to minimize this effect. First, only a portion of the animals' diet was medicated and this was offered first; secondly, animals were fed to less than appetite so that each meal was consumed quickly.

In the results shown in Table 4 the former approach was adopted and the medication was given in $100 \mathrm{~g}$ cattle concentrate. This reduced the average methane production, measured in samples removed at intervals from the group of six animals, from the untreated value of 23.1 to $4.7 \mathrm{ml} / 1(P<0.01)$ during the first 2 weeks and from $24.5-11.1 \mathrm{ml} / 1$ $(P<0.01)$ during the second 2 weeks. During the first 2 weeks there was a statisticallysignificant increase $(P<0.02)$ in the concentration of propionic acid in the rumen contents of the treated animals accompanied by a non-significant increase in butyric and a decrease (also non-significant) in the concentration of acetic acid. These trends continued during the second 2 weeks when the dose of compound was reduced to $30 \mathrm{mg}$ daily but the statistical significance of the effect on rumen propionic acid concentration was lost.

\section{Administration of ICI 13409 to cattle}

Preliminary experiments with intraruminally-dosed ICI 13409 showed that single doses of 1 or $2 \mathrm{mg} / \mathrm{kg}$ body-weight gave mild transitory inhibitions of methane production, doses of 3 or $4 \mathrm{mg} / \mathrm{kg}$ body-weight gave much more pronounced inhibitions with methane production still below control values after $24 \mathrm{~h}$, whilst larger doses gave almost total inhibition which lasted for $24 \mathrm{~h}$ with slow recovery of methane production during the next 
Table 4. Effect of dietary administration of 2,4-bis-(trichloromethyl)-benzo[1,3]dioxin-6-carboxylic acid to sheep

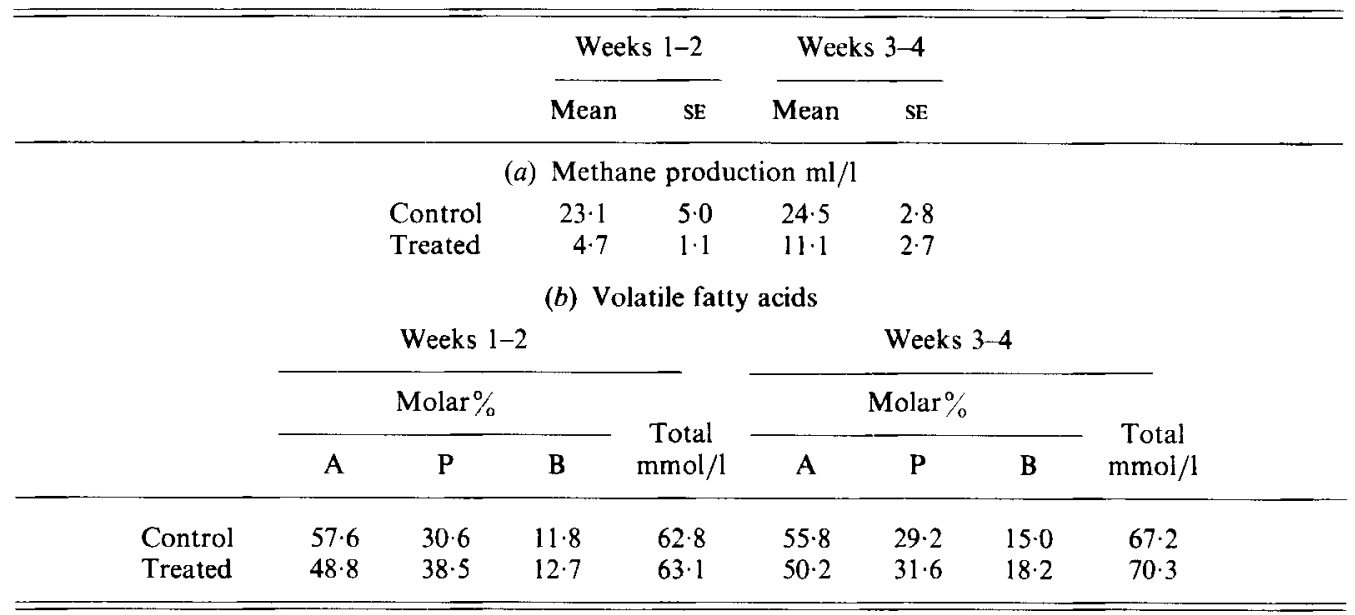

Table 5. Effect of dietary administration of 2,4-bis (trichloromethyl)-benzo[1,3]dioxin-6-carboxylic acid to cattle

(Mean values with their standard errors. Day 1 represents the effect of the first dose of compound. The mean pre-treatment value of the eight animals each sampled several times was $28.8 \pm 2.7 \mathrm{ml} / \mathrm{l}$ )

\begin{tabular}{|c|c|c|c|c|c|c|}
\hline \multirow[b]{4}{*}{ Group... } & \multicolumn{6}{|c|}{ Methane production $\mathrm{ml} / \mathrm{l}$} \\
\hline & \multirow{2}{*}{\multicolumn{2}{|c|}{ Untreated }} & \multicolumn{4}{|c|}{ Treated } \\
\hline & & & \multicolumn{2}{|c|}{$4 \mathrm{mg} / \mathrm{kg}$} & \multicolumn{2}{|c|}{$6 \mathrm{mg} / \mathrm{kg}$} \\
\hline & Mean & $\mathrm{SE}$ & Mean & SE & Mean & SE \\
\hline Day of trial: 1 & $25 \cdot 0$ & $3 \cdot 4$ & $12 \cdot 0$ & $3 \cdot 0$ & $7 \cdot 0$ & $2 \cdot 0$ \\
\hline $2-5$ & $35 \cdot 5$ & $8 \cdot 4$ & $2 \cdot 2$ & $0 \cdot 3$ & $2 \cdot 0$ & $0 \cdot 1$ \\
\hline $8-11$ & $35 \cdot 3$ & $4 \cdot 5$ & $2 \cdot 0$ & 0.5 & $2 \cdot 0$ & $0 \cdot 3$ \\
\hline $15-19$ & $28 \cdot 2$ & $2 \cdot 2$ & $3 \cdot 0$ & $0 \cdot 3$ & 1.5 & 0.4 \\
\hline $22-23$ & $32 \cdot 0$ & $3 \cdot 0$ & $4 \cdot 0$ & 1.4 & $2 \cdot 5$ & 0.4 \\
\hline
\end{tabular}

$24 \mathrm{~h}$. Two groups of three calves were given concentrate containing ICI 13409 in quantities calculated to dose the animals with respectively 4 and $6 \mathrm{mg} / \mathrm{kg}$ body-weight. Samples of rumen contents were withdrawn and compared with samples of rumen contents from untreated animals for ability to produce methane in vitro. Results shown in Table 5 indicate a marked depression of methane production which persisted throughout the $23 \mathrm{~d}$ of the experiment. These effects are highly significant $(P<0.001$; Student's $t$ test on the logarithm of the values) after day 1 .

\section{Cattle growth trial}

The results are shown in Tables 6 and 7; statistical analysis has been carried out on the whole trial and also on the first and last 14 weeks. This was possible since the average weight of the animals did not differ significantly at the end of week 14. The trend however was for 
Table 6. Effect of 2,4-bis (trichloromethyl)-benzo[1,3]dioxin-6-carboxylic acid (ICI 13409) and monensin (Romensin; Elanco PLC) on growth of beef cattle

(Mean values; values in parentheses show percentage changes from the untreated animals; an analysis of variance was performed on the pen mean responses allowing for the effects of the rows and columns of the $4 \times 4$ Latin square and the treatment groups; treatment means were compared to the control using Student's $t$ test with 1 -sided significance levels where the standard error was derived from the residual mean square in the ANOVA)

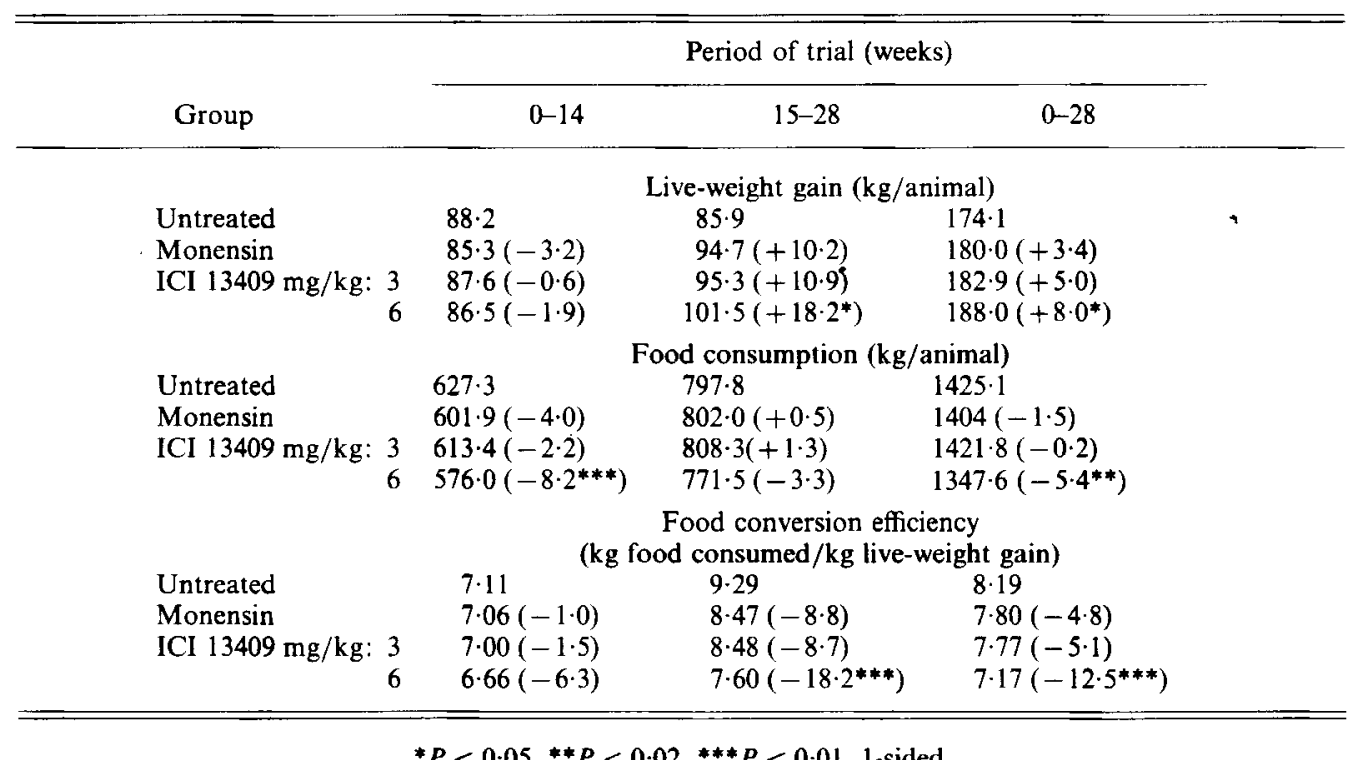

${ }^{*} P<0.05,{ }^{* *} P<0.02,{ }^{* * *} P<0.01,1 \cdot$ sided

Table 7. Effect of ICI 13409 and monensin (Romensin; Elanco PLC) on methane production and energy retention in beef cattle

(Values in parentheses show percentage changes from the untreated animals)

\begin{tabular}{|c|c|c|c|c|c|}
\hline \multirow[b]{3}{*}{ Group } & \multirow{3}{*}{$\begin{array}{c}\text { Energy retention } \\
\text { (MJ metabolizable } \\
\text { energy in diet) }\end{array}$} & \multicolumn{4}{|c|}{$\begin{array}{l}\text { Methane production } \\
\text { ( } \mathrm{ml} / 1 \text { in hood gas) }\end{array}$} \\
\hline & & \multicolumn{2}{|c|}{ Weeks $0-3 \dagger$} & \multicolumn{2}{|c|}{ Weeks $0-28 \dagger$} \\
\hline & & Mean & $\mathbf{S E}$ & Mean & $\mathrm{SE}$ \\
\hline Untreated & $6 \cdot 58$ & $1 \cdot 3$ & 0.15 & 1.9 & $0 \cdot 10$ \\
\hline Monensin & $5.95\left(-9.6^{*}\right)$ & 0.8 & $0 \cdot 10$ & 1.5 & $0 \cdot 10$ \\
\hline $\begin{array}{c}\text { ICI } 13409 \\
3 \mathrm{mg} / \mathrm{kg}\end{array}$ & $5.89\left(-10 \cdot 5^{*}\right)$ & 0.5 & 0.03 & $1 \cdot 1$ & 0.06 \\
\hline $\begin{array}{c}\text { ICI } 13409 \\
6 \mathrm{mg} / \mathrm{kg}\end{array}$ & $5 \cdot 59\left(-15 \cdot 0^{* *}\right)$ & $0 \cdot 1$ & 0.02 & 0.7 & 0.05 \\
\hline
\end{tabular}

${ }^{*} P<0.05,{ }^{* *} P<0.01$.

$\dagger$ Period of trial. 
all treatments to depress both weight gain and food intake during the first half of the trial but only in the $6 \mathrm{mg}$ ICI $13409 / \mathrm{kg}$ group was the food intake depressed by a statisticallysignificant amount $(P<0.01)$. During the second half of the trial the growth rate of the treated animals improved being 10,11 and $18 \%$ better than the control animals for the groups treated with monensin, ICI $134093 \mathrm{mg}$ and $6 \mathrm{mg} / \mathrm{kg}$. Only in the latter instance was the improvement significant $(P<0.05)$ and here also the food intake was still less than the control. The combined effect was a highly-significant $18 \%(P<0.01)$ improvement in food conversion efficiency. Over the 28 weeks of the trial all treatments tended to improve growth with marginal depression of appetite, the net result being an improvement in food conversion efficiencies of 5 (not significant), 5 (not significant) and $13 \%(P<0.01)$ for the animals treated with respectively monensin, 3 and $6 \mathrm{mg} \mathrm{ICI} 13409 / \mathrm{kg}$.

When each pen of animals reached a mean live-weight of $386 \mathrm{~kg}$ they were slaughtered and the carcasses were analysed for their content of dry matter and protein. This enabled the conversion of dietary energy into energy retained in the animal to be calculated. All treatments improved the energy conversion ratio by 10,11 and $15 \%$ respectively for monensin, 3 and $6 \mathrm{mg} \mathrm{ICI} 13409 / \mathrm{kg}$. These effects were all statistically significant.

The production of methane was checked by measuring the concentration in a metabolic respiration hood at equilibrium. In all instances this concentration was higher during the latter weeks of the trial than at the beginning. Treatment with monensin gave a small reduction in methane production (significant at $P<0.1$ only; Student's $t$ test on the logarithms of the methane concentrations) whilst treatment with ICI 13409 gave more pronounced inhibition which was highly significant $(P<0.001$ high dose and low dose over 28 weeks; $P<0.01$ low dose first three weeks). In all instances the effects were maintained throughout the trial.

\section{DISCUSSION}

Most members of the series of 6-substituted 2,4-bis(trichloromethyl)-benzo[1,3]dioxins show good activity in inhibiting methane production by rumen contents incubated anaerobically in vitro. The best of these gave approximately $70 \%$ reduction in methane production at $1 \mu \mathrm{g} / \mathrm{ml}$, or approximately $2.5 \mu \mathrm{mol} / 1$. There was a concomitant stimulation of hydrogen production, not exceeding $25 \%$ of the reduction in methane. This makes them at least twice as potent as the best of the compounds studied by Czerkawski \& Breckenridge $(1975 a)$. In view of the variable results reported in the literature on a number of halogenated inhibitors of methanogenesis it seemed essential to get an early evaluation of potency in vivo. The simple single dose test used showed that only two derivatives, the 6-carboxylic acid and the 6-carboxamide were capable of sustained high levels of inhibition at a dose of $1.2 \mathrm{mg} / \mathrm{kg}$ body-weight. A few more compounds, notably the 6-sulphonamide, the 6-trichloromethyl-carboxylic ester and the 6-chloride were effective at higher doses. Thus, the physio-chemical requirements for activity are far more severe for the in vivo situation.

Further work was therefore restricted to the 6-carboxylic acid and 6-carboxamide derivatives with the former being favoured on grounds of ease of chemical synthesis and hence cost of compound. Both compounds were able to control methane production at the expense of stimulating hydrogen formation by sheep for extended periods when dosed daily into the rumen. There was a decrease in the concentration of acetate in the rumen fluid and an increase of propionate. Some preliminary work with administration of ICI 13409 in the diet indicated that the diet had to be consumed fairly quickly for optimal activity of the compound.

Provided that the compound was rapidly consumed by sheep, daily administration of $30 \mathrm{mg}$ gave an approximate $50 \%$ reduction in methane output and slight increases in the concentration of ruminal propionic acid. At $60 \mathrm{mg} /$ animal per d methane production was 
reduced by more than $75 \%$, propionate was markedly increased and acetate reduced. Dietary administration of ICI 13409 to cattle also caused a marked depression in methane production. The reduction was maintained with a slight upward trend towards the end of the experiment but this was small in relation to the magnitude of the inhibition of methane production.

This led us to believe that if most of the dietary $\mathrm{C}, \mathrm{H}$ and energy normally eructed as methane were being converted into products useful to the host animal, then it should be possible to detect a growth-promoting response in animals. Such an effect was in fact obtained in a 4-week trial in sheep but the variable live-weight gain was $(0.05>P<0 \cdot 1)$. Therefore, a definitive trial was conducted in cattle and continued for 28 weeks to minimize the effects of weighting variability. Thereafter groups of animals were slaughtered as their average weight reached $386 \mathrm{~kg}$, this being done to ensure consistency of energy and protein requirements for growth. Changes in the efficiency of utilization of the diet will then be manifest as a variable requirement for maintenance since the slower growing animals will have a higher maintenance requirement over the period of time to attain a pre-determined live weight than rapidly growing ones. The ionophoric antibiotic monensin was included to give a group of positive control animals as well as the negative control or untreated animals.

In the first half of the trial, both the ICI compound, selected for its inhibition of methanogenesis and the antibiotic monensin depressed growth and food consumption slightly. The depression of food intake was statistically significant $(P<0.01)$ for the group of animals treated with $6 \mathrm{mg}$ ICI $13409 / \mathrm{kg}$. In the second half of the trial, growth of all treated animals was stimulated with respect to the untreated animals, the effect being statistically significant $(P<0.05)$ in the groups treated with $6 \mathrm{mg} \mathrm{ICI} 13409 / \mathrm{kg}$. These animals also had significant $(P<0.01)$ improvements in food conversion ratio, while the positive effects recorded for the other treatment groups failed to reach significance at the $P=0.05$ level. Over the trial as a whole the animals treated with $6 \mathrm{mg} \mathrm{ICI} 13409 / \mathrm{kg}$ grew faster $(P<0.05)$, ate less $(P<0.02)$ and had much improved food conversion ratios $(P<0.01)$ than untreated animals.

Energy retention was measured by a chemical analysis of the carcass, washed gastrointestinal tract and offal, which were analysed separately and the values then pooled and comparison of this with the calculated metabolizable energy of the diet. On this basis all treatments significantly improved conversion of dietary energy into energy retained in the animal. Estimates of energy lost as methane in expired gases were made intermittently for 10 min periods on the same pen of four animals from each treatment. This was thought to be the maximum interference which could be tolerated by the trial animals. Analysis of the performance of these animals revealed no significant differences from animals not subjected to this interference so perhaps more analysis for methane output could have been made. The values obtained indicate that all treatments reduced methane output in comparison with the untreated animals, the effect being least with monensin but even in this instance significant at the $P<0.1$ level. It has frequently been observed that methane inhibition, especially with halogenated compounds, causes an accumulation of hydrogen gas in the rumen. It is evident that this process also results in a loss of energy for the host animal. The authors have not measured hydrogen gas in their growth trial.

Thus, a sustained reduction in methanogenesis can be obtained in a typical indoor feeding situation for beef cattle and whilst we have no direct evidence that this correlates with any benefit, the animals improvements in energy retention were measured. With regard to food conversion ratio, a factor of more practical importance in commercial farming than energy retention, the response was critically related to dose. The small effects noted with the low dose of ICI 13409 or with monensin would be difficult to assess whereas the $15 \%$ 
improvement with the high dose of ICI 13409 would be much more obvious. There is no information regarding the safe upper limit for inclusion of this compound but it is typical of highly-halogenated chemicals in general that overdosing results in severe depression of appetite and loss of performance.

Use of halogenated compounds has also resulted in a lower $\mathrm{NH}_{3}-\mathrm{N}$ concentration in the rumen (Trei et al. 1971, 1972). This indicates a lowered feed protein degradation, with a possible beneficial effect on the growth parameters of the animal. The authors did not determine $\mathrm{NH}_{3}-\mathrm{N}$ concentrations. More research on the effect of the drug on protein metabolism is desirable.

The benzo-dioxin series of compounds were synthesized by Dr F. T. Boyle and Messrs R. Brown and M. A. Taylor in the Alderley Park Laboratories, and have patented for application in ruminant animals (Boyle \& Davies, 1977). An analysis of variance of the cattle trial results was conducted by Dr R. A. Ferguson. The authors thank Miss Sally M. White (Department of Biological Science, Hatfield Polytechnic, seconded for 1 year's Professional Training) for valuable technical assistance; also the staff of Alderley Park Farm for care and maintenance of the experimental and trial animals.

Bergman, C. (1964). J. Am. vet. Res. $25,848$.

\section{REFERENCES}

Boyle, F. T. \& Davies, A. (1977). U.K. Patent 1502116.

Clapperton, J. L. (1977). Anim. Prod. 24, 169.

Cole, N. A. \& McCroskey, J. E. (1975). J. Anim. Sci. 41, 1735.

Czerkawski, J. W. \& Brekenridge, G. (1975a). Br. J. Nutr. 34, 429.

Czerkawski, J. W. \& Brekenridge, G. (1975b). Br. J. Nutr. 34, 447.

Johnson, D. E. (1972). J. Anim. Sci. 35, 1064.

McBride, B. C. \& Wolfe, R. S. (1971). Nature, Lond. 234, 551.

Rufener, W. H. Jr \& Wolin, M. J. (1968). Appl. Microbiol. 16, 1955.

Sawyer, M. S., Hoover, W. H. \& Sniffen, C. J. (1974). J. Anim. Sci. 38, 908.

Stanier, G. \& Davies, A. (1981). Br. J. Nutr. 45, 567.

Trei, J. E., Parish, R. C., Singh, Y. K. \& Scott, G. C. (1971). J. Dairy Sci. 54, 536.

Trei, J. E., Scott, G. C. \& Parish, R. C. (1972). J. Anim. Sci. 34, 510.

Van Nevel, C. J., Henderickx, H. K., Demeyer, D. I. \& Martin, J. (1969). Appl. Microbiol. 17, 695. 